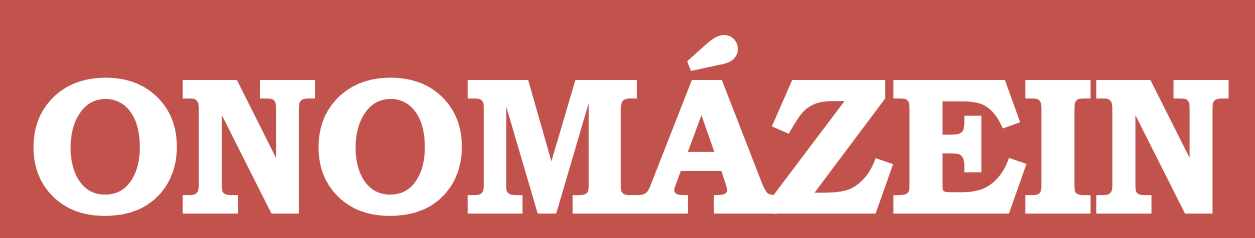

Journal of linguistics, philology and translation
PONTIFICIA UNIVERSIDAD

CATÓLICA DE CHILE FACULTAD DE LETRAS

\title{
A multicompetence perspective of hedging in second language academic writing
}

\author{
Rosa Alonso Alonso \\ Universidad de Vigo \\ España
}

ONOMÁZEIN 45 (September 2019): 58-78

DOI: 10.7764/onomazein.45.02

ISSN: 0718-5758

\section{(c) $\odot$}

Rosa Alonso Alonso: Departamento de Filología Francesa, Inglesa y Alemana, Universidad de Vigo, España. | E-mail: ralonso@uvigo.es 


\section{Abstract}

Most studies on hedging in second language academic writing include data in the second language or in both the first (L1) and the second language (L2) but not data from the same participants in both their L1 and L2. Following the multicompetence framework (Cook, 2012; Cook and Li, 2016; Ortega, 2016), this paper analyses hedging in L2 writing by examining the use of hedges in a group of 24 Spanish learners of English as a L2, both in their L1 and in their L2 in order to have evidence from the learners' total system, as well as two baseline control groups of 24 native speakers of Spanish and 24 native speakers of English. This study also investigates crosslinguistic influence and convergence in the use of hedges. Hedges were coded following Hyland's (1994) typology. Chi-square analyses revealed differences between English and Spanish speakers. English speakers and L2 learners also showed differences in the use of hedging devices indicating impersonal expressions and lexical verbs. Findings in the Spanish native control group and Spanish learners of L2 English in their L1 Spanish showed differences in the use of adverbs and nouns. Evidence of crosslinguistic influence was found and findings showing LI-L2 similarity in the use of adverbs in the learners' group indicated LI-L2 convergence.

Keywords: hedging; second language; writing; multicompetence; crosslinguistic influence. 


\section{Introduction}

Hedging refers to linguistic expressions whose purpose is to present information with the appropriate level of caution and certainty (Hyland, 1994). For example, the statement "The results in this paper are conclusive" can be interpreted as too direct or unpolite by the reader, however if a hedging device, such as the lexical verb seem, is added, the statement is more cautious: "The results in this paper seem to be conclusive". In academic writing hedging is an important issue as effective academic writing requires information to be presented in an objective way but at the same time the writers should not be too strong when defending their position. Hedging devices are used to convey their statements in a cautious way. These devices tend to be learnt through practice and/or teaching. It is generally a taught skill and is not necessarily a part of the average native speaker competence; in fact many first language students may not have this skill and need to be trained to write their compositions and assignments.

In second language writing, the task of using hedges is a complex one as learners usually find it difficult to express doubt or certainty in a language which is not their LI (Clyne, 1987; Holmes, 1982; Scarcella and Brunak, 1981) but they are faced with the challenge of writing in English in their BA, MA or PhD project. Thus, students of English as a L2 tend to be trained in order to develop this skill and be able to use hedging effectively, and many BA and MA programmes incorporate academic writing courses in their curricula, which include the study of hedging devices. Most studies on hedging in L2 writing have focused on analyzing the written production and/or comprehension in the L2 while some of them also offer L1-L2 comparisons. However, research in L2 academic writing has tended to neglect the performance of the same group of learners in both their native language and their L2, offering only a limited picture of the learners' total system. Following the multi-competence framework (Cook, 2003, 2012; Cook and Li, 2016; Ortega, 2016), which states that second language acquisition does not only involve the L2 but also the whole mind of the L2 user, the present study aims to fill a gap in the literature by analysing the production of hedges in L2 writing by three groups of speakers, who have all attended academic writing courses in their respective universities: monolingual native Spanish speakers, monolingual native English speakers and Spanish learners of English as a L2. In the learners' group, data have been collected, both in their L1 and their L2 in order to have evidence from the learners' total system. This will allow us to analyze four main issues regarding the use of hedging in academic writing: a) whether monolingual Spanish speakers will differ from monolingual English speakers, b) whether L2 learners will differ from L1 English speakers, c) whether L1 Spanish speakers learning English as a L2 will differ from LI monolingual Spanish speakers, and d) whether there will be crosslinguistic influence and convergence across groups.

The study is divided as follows: section 2 focuses on hedging in academic writing and section 3 deals with hedging in L2 writing. In the following sections, the empirical study is developed. Finally, Section 6 includes the conclusion. 


\section{Hedging in academic writing}

As Lakoff (1972: 195) pointed out, hedging can be defined as words or phrases "whose job is to make things fuzzier". Hedging devices in academic writing have been a commonly analysed feature (Bloor and Bloor, 1991; Hyland, 1994, 1998; Hyland and Milton, 1997; Myers, 1989; Salager-Meyer, 1994; Skelton, 1988a, 1988b; Marta, 2017). Epistemic modality lies at the basis of academic writing, an idea that is present in Lyons" definition of hedging as "any utterance in which the speaker explicitly qualifies his commitment to the truth of the proposition expressed by the sentence he utters in an epistemically modal or modalised sentence" (1977: 797). The use of tentative language has the intention of reducing the degree of liability of the author (Huebler, 1983: 18) with the final aim of making the argumentation more effective.

Much research in academic writing has focused on the use of hedging as a strategy to convey politeness. It is considered to have a protective function as a way of avoiding face-threatening acts, i.e. knowledge claims, thus acting as face protection (Brown and Levinson, 1987). Nevertheless, hedging is not always the result of avoiding face threatening acts or motivated by politeness. It can also be utilized for epistemic and interpersonal reasons. Mauranen (1997) states that it is epistemic when an author suggests that a state of affairs is open to interpretation and interpersonal when the author's face is protected so that tentative language is used to minimize criticism. The context disambiguates whether it is being used for epistemic or interpersonal reasons. As the line between both types can be blurred, Mauranen prefers to talk about primarily epistemic or primarily interpersonal. The interpersonal nature of hedging has also been emphasized by Hyland (1994) since it supports the writer's position but also establishes a connection between the writer and the reader as hedging helps the reader to make cautious statements.

In this paper we will follow Hyland's (1994) typology for lexical markers of hedging (modal verbs, lexical verbs, adverbs, time reference adverbials, nouns, and adjectives) and structural elements (if-clauses, question forms, impersonal expressions, passivization). In Hyland's words: "Typically hedging is expressed through modal auxiliary verbs such as may, might and could, adjectival, adverbial and nominal modal expressions (possible, perhaps, probability), modal lexical verbs (believe, assume), if-clauses, question forms, passivisation, impersonal phrases, and time reference "(Hyland, 1994: 240). This typology has been chosen as it has been widely used in the literature and it allows us to obtain a detailed classification of the hedging devices used by the participants.

Although cross-cultural aspects fall beyond the scope of this paper, it is imperative to mention that interest has increased on cross-cultural studies such as Ventola and Mauranen (1990), Clyne (1991), Kreutz and Harres (1997), Vassileva (1997). Some studies defend that the use of hedging is culture-specific and that it varies in L1 and L2 speakers (Bloor and Bloor, 1991). In Clyne's (1991) study on English and German, German speakers were found to use 
hedging more extensively and in more complex structures than English speakers. In contrast, Trumpp (1998) in a study with German, English and French speakers found out that German and French used less hedges than English. Breitkopf $(2005,2006)$ also points out that there are culturally-related differences in frequency and functions as well as in the preferences shown in German and Russian research papers in the field of sociology. Cross-cultural differences were also observed by Vassileva (1997) in a study on British and American English compared with Bulgarian. It was found out that English speakers used more hedges and Bulgarians preferred different types of hedges.

\section{Hedging in L2 writing}

Second language writers usually find it difficult to express hedges in English as a second language. Some studies have indicated difficulties in acquiring hedges in a L2 (Clyne, 1987; Holmes, 1982; Scarcella and Brunak, 1981; Skelton, 1988a), the most problematic issues being the production of unhedged passages which are too direct for readers or the lack of modulation showing pragmatic unawareness of how academic conventions work in the L2 becoming inappropriate of event offensive for an English L1 reader. Following this line of argumentation, Hyland and Milton (1997) in a comparative study conducted with British and Chinese speakers concluded that Chinese learners used simpler constructions and showed more problems in conveying certainty. Hinkel (2005) analyzed the types and frequencies of hedges and intensifiers in L1 and L2 speakers. L2 writers proved to use significantly less hedging devices than L1 speakers in their essays. In a later study this author (2009) analyzed the use of modal verbs in a corpus of L1 and L2 writing (718 essays / 201,601 words) on five different topics written by speakers of English, Chinese, Korean, and Japanese. The results showed that the writing topic affected the frequency rates of modal verbs in L2 essays depending on the Lis and the contextual meanings and functions of obligation and necessity modals. The topics which were less personal indicated fewer differences between $L 1$ and $L 2$ than topics where the students needed to focus on their personal experiences. Although the Li has been found to play an important role in the use of hedges, Hyland (2000) in a study conducted with 14 Cantonese students at the University of Hong Kong comparing hedges and boosters found out that hedges appear to be less visible, and although differences were found between native and nonnative speakers, it was found difficult to assign differences on the basis of the L1 as they might be due to the language proficiency of the subjects, rather than to the effect of the $L 1$.

Most studies compare one or different LIs with the written production of those subjects in the L2. These studies typically include data in the L2 of learners from different LIS (Archibald, 2001; Hinkel, 2009; Nurmukhamedov and Kim, 2009) or data in the L1 and in the L2 of learners from the same LI (Choi and Ko, 2005; Poveda Cabanes, 2007; Chen, 2010). Data from the same participants in both their $L 1$ and $L 2$ is generally left out of the equation as data are in the best of cases only collected in the LI and the L2 but not from the same participants, 
i.e. a group in the LI is compared with a group in the target language, in other words, native speakers are compared with nonnative speakers which inhibits having the whole picture of the participants' total system.

The multicompetence framework proposes including all languages in the learner's total system. Multi-competence is defined as "the knowledge of more than one language in the same mind or the same community" (Cook, 2012: 3768), i.e. bi/multilingual minds are characterized by knowing two or more languages, this makes $L 2$ users different from monolinguals and more importantly not deficient as compared to monolinguals (Cook, 2012: 3768). Research on hedging has tended to focus on studies on the perception and/or production of specific issues in the L2 by collecting data in the interlanguage of the learners and typically having either no LI comparison or having a control group ranging from one native monolingual group to more than one native monolingual group.

Multicompetence studies, as well as bi/multilingual studies favour including data from the same participants in the $L 1$ and $L 2$, together with sample control groups of native speakers both in the $L 1$ and the $L 2$ (see Ortega, 2016). Without evidence of the participants' Ianguage pairs, be it LI-L2 or LI-L2-Ln, it is not possible to know how the acquisition of a L2 works as an important part of the puzzle is missing and the influence of the $L I$ is assumed rather than proved. Research in multicompetence proposes including the total system of the participants, i.e. their LI, their L2 and their Ln when it applies. Data should then include tasks that the participants undertake in their L1 and their L2 and in their Ln in cases of multiple language acquisition. L2 users have more than one language in their minds, ignoring this and collecting data only in their $\mathrm{L} 2$ is in sharp contrast with a bi/multilingual perspective. For this reason, we consider it necessary, in line with Cook (2016) and Ortega (2016), to analyse data in the participants' language pairs (LI-L2) or (LI-L2-Ln).

In the present study hedging devices are analysed in Spanish (L1) and English (L2) by the same participants who are Spanish native speakers learning English as a Second Language. Additionally, data have been collected from monolingual Spanish Lı speakers and monolingual English Lı speakers. Similar studies were conducted by Brown and Gullberg $(2008,2013)$ in the field of motion events, providing solid evidence of multicompetence effect. Although our area of research is not motion events but hedging, we believe this research design is the most fruitful as it allows us to cover the total system of all the languages co-existing in the learners' single minds and observe how this is reflected in their use of hedges in L2 academic writing.

Covering the total system also allows us to obtain evidence of crosslinguistic influence in the use of hedges and how it can influence the different languages co-existing in the learner's mind. Many studies on crosslinguistic influence assume it but do not prove its occurrence as data are only collected in the L2 (cf. Ortega, 2016). In contrast, in multicompetence studies data are collected in the learner's total system as it covers the total system of all languages 
in the same mind. As Cook mentions, "crosslinguistic influence takes on a different meaning in multicompetence (...): the LI part of the system may influence the $L 2$, the $L 2$ may influence the $L 1$, the $L 3$ may influence the L2" (2016: 10). Thus, hedging in the $L 1$ may influence it in the $\mathrm{L} 2$ and viceversa and this interaction is continuous in the learner's mind.

On the other hand, in a study which includes the learners' total system, convergence should also be considered. Convergence of usage patterns is generally used to refer to similarity between the two languages of a bilingual which is related to the optional choices available in one of the languages of the bilingual. In second language acquisition, convergence has been analysed mainly in the area of motion events. For example, Brown and Gullberg (2010) compared monolingual speakers of Japanese resident in Japan and monolingual speakers of English in the USA with native Japanese speakers with knowledge of English resident in Japan and native Japanese speakers with knowledge of English resident in the USA. Their findings indicated that monolinguals showed morphosyntactic preferences for the expression of Path while learners used both verbs and adverbials for the encoding of Path both in their L1 and L2 indicating convergence between the two systems. It was also shown that bilingual speakers construed motion events in a different way from monolingual speakers of their L2 and from monolingual speakers of their L1 suggesting restructure of linguistic conceptualization.

In the field of hedging in L2 writing, to the best of our knowledge, no study has thus far considered the analysis of the hedges produced by the same group of participants in both their $L 1$ and their L2, including baseline control groups of the respective L1S, in this case Spanish and English. In addition, most studies on convergence (Bullock and Toribio, 2004; Backus, 2004; Treffers-Daller and Mougeon, 2005) tend to focus on balanced functional bilinguals rather than on speakers with lower proficiency in the $L 2$. In the present study we analyze the language produced by Spanish learners of English (B2 level according the Common European Framework of Reference for Languages) who are not functional bilinguals. This will allow us to have a clear distinction of crosslinguistic influence from the effects of bilingualism that have been considered so far, providing us with the methodological rigor necessary to distinguish crosslinguistic influence (cf. Jarvis, 2002). Moreover, it will allow us to establish which differences are due to the LI since all participants show the same proficiency level (B2). Finally, evidence of convergence may indicate a multicompetent construct and, if evidence is found in our study, it will also indicate that lower levels of proficiency (B2) result in co-existence of a common construct when there is knowledge of more than one language in the same mind even with limited exposure to the $L 2$.

The study stems from the following research questions:

1. Will monolingual Lı Spanish speakers differ from monolingual Lı English speakers in their use of hedges? 
2. Will L2 learners differ from L1 English speakers in their use of hedges?

3. Will Lı Spanish speakers learning English as a second language differ from Lı monolingual Spanish speakers in their use of hedges in the LI?

4. Will there be evidence of crosslinguistic and/or convergence influence across groups?

\section{The study}

\subsection{Participants}

Three groups of participants have taken part in the study: 24 Spanish speakers learning English as a L2 and two monolingual groups: 24 L1 English and 24 LI Spanish speakers. All groups answered a questionnaire which focused on whether they had attended academic writing courses and were familiar with composition/essay writing. All participants reported having attended a one-semester academic writing course in their respective universities and being familiar with composition and essay writing.

The L2 group carried out the Oxford Quick Placement test (2001), their level was B2 according to the Common European Framework of Reference for Languages. Their mean age was 19.3 and there were 4 male and 20 female. They were all studying their second year in the degree of Foreign Languages at a Spanish university. The learners' group also conducted the test on language use by Gullberg and Indefrey (2003). It revealed that they used English daily at the university, they wrote all their papers and exams in English and they studied English a mean of 2 hours a week on their own.

The monolingual native control groups answered a short language background questionnaire so as to obtain information on their language usage. It provided information on their age, gender, their possible knowledge and their use of any foreign language. In a multilingual society it is difficult to find utterly monolingual subjects, so the selected subjects are "minimally bilingual", as stated in Cook (2003: 14). Participants who studied Spanish or used it daily or had been living in a foreign country were discarded from the study. The selected English Lı speakers were a mean of 20.4 years old, there were 14 male and 10 female. They were all university students. They did not speak any foreign language and they have never been in a Spanish-speaking country.

As regards Lı Spanish speakers, they were a mean age of 18.9, there were 6 male and 18 female. They were University students. Six of them reported having done a beginner course in French, Italian or German at school. None of them is bilingual, has an intermediate or advanced level of proficiency in English. They have never lived or visited an English speaking country, they did not use English daily, they did not write in English and they are not doing any English course at present. 


\subsection{Material and procedures}

The data collection material consisted of a composition which follows the model of the International English Language Testing System writing tasks, where students are asked to produce a written argument of a given topic of 250 words. The topic of the composition was "Some people believe the aim of University education is to help graduates get better jobs. Others believe there are much wider benefits of university education for both individuals and society. Discuss both views and give your opinion". Participants produced the writing outside of class hours. They were not allowed to use dictionaries or any other materials and they were allotted two hours. The language order was counterbalanced for the learners' group. They produced first the task in English and three weeks later the same task in their LI (Spanish) so as to avoid any language mode effects (Grosjean, 1998: 132). The monolingual groups conducted the task only in their L1.

\subsection{Data analysis and results}

Following the multicompetence framework (Cook, 2012, 2016; Ortega, 2016), data have been collected from baseline native control groups of Spanish and English speakers and data from L2 learners in their two languages, their LI (Spanish) and their L2 (English), i.e. the analysis included both languages by the same speakers, as the following table indicates.

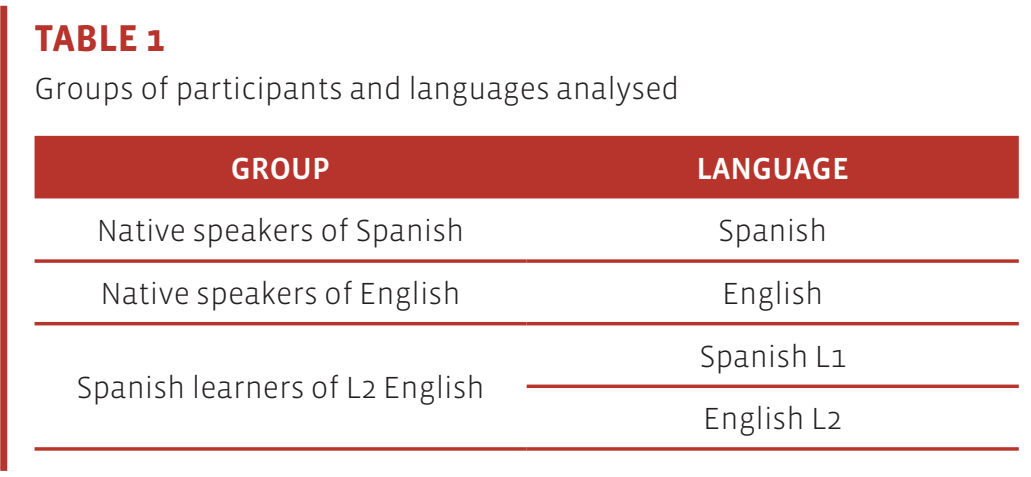

Data were also coded by type of hedging device, i.e. the hedges each participant produced were coded into the types of hedging proposed by Hyland (1994), as mentioned in section 1. Comparisons were made by group, thus four comparisons were conducted: a) English and Spanish native control groups use of hedges, b) English L2 learners use of hedges in their L2 and in their L1, c) English native control group and Spanish learners use of hedges in their L2 English, d) Spanish native control and Spanish learners of L2 English use of hedges in Spanish. The control groups were compared first so as to have the baseline data that would allow us to determine the possible occurrence of crosslinguistic influence. 
Participants were asked to produce 250 word compositions. Groups differed in the number of hedging devices they produced, as can be observed in table 2:

\section{TABLE 2}

Number of hedging devices used by the three groups of speakers

\begin{tabular}{cccc}
\hline $\begin{array}{c}\text { English native } \\
\text { speakers }\end{array}$ & $\begin{array}{c}\text { Spanish native } \\
\text { speakers }\end{array}$ & $\begin{array}{c}\text { Spanish learners } \\
\text { of English } \\
\text { (Spanish L1) }\end{array}$ & $\begin{array}{c}\text { Spanish learners } \\
\text { of English } \\
\text { (English L2) }\end{array}$ \\
\hline 182 & 236 & 235 & 260 \\
\hline
\end{tabular}

Chi-square analysis revealed that English LI speakers in the control group and Spanish native speakers in the control group showed significant differences in the number of hedges produced $(p=0.008)$, i.e. Spanish native speakers in the control group used more hedges than English native speakers, as can be observed in table 2. With regard to the comparison between English L1 speakers and L2 learners of English, a significant difference was found in the use of hedges ( $p=0.000)$, L2 learners employed more hedges than English native speakers did. The comparison between the number of hedges produced by Spanish native speakers in the control group and Spanish learners of $L 2$ in their L1 yielded no significant differences. No significant differences in the number of hedges used were found between the Spanish native speakers control group and the group of L2 learners in their L1.

We will now focus on the four comparisons addressed in the study. All tables indicate the percentage of hedging devices used, with raw figures in parentheses, as well as chi-square and p-values. Significant differences are indicated with an asterisk. The significance level is set in $p<0.05$.

\subsubsection{English and Spanish native control groups use of hedges}

Table 3 shows the number of hedging devices produced by the English and the Spanish native speakers' control groups in their respective Lis (see the table on the next page).

As can be observed in table 3, English and Spanish speakers behaved in a similar way in the use of adjectives, if-clauses, lexical verbs, nouns, passivization and questions forms as hedging devices. In contrast, significant differences were found in the use of adverbs, impersonal expressions, modal verbs and time reference. Spanish speakers used adverbs as hedging devices more frequently than English speakers did. Chi-square analysis found this difference to be significant ( $p=0.005$ ). For instance, subject 4 used the adverb "tremendamente" (tremendously): "la experiencia universitaria favorece un intercambio de opiniones y un pensamiento crítico, que son ambos tremendamente útiles para nuestras vidas" (university experience favours exchanging opinions and critical thinking; both are tremendously useful for our lives). 


\section{TABLE 3}

Use of hedging devices by English and Spanish native speakers

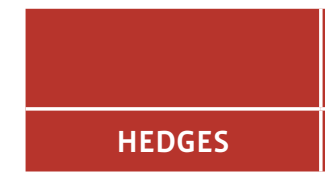

ENGLISH NATIVE
SPEAKERS

\section{SPANISH NATIVE} SPEAKERS

\begin{tabular}{l} 
Adjective \\
\hline Adverb
\end{tabular}

$10.99(20)$

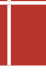

If-clause

18.13 (33)

$8.47(20)$

CHI-SQUARE

P VALUE

Impersonal

expression

5.49 (10)

$30.51(72)$

0.488

0.485

\begin{tabular}{lcccc}
\hline Lexical verb & $24.73(45)$ & $19.49(46)$ & 1.360 & 0.244 \\
\hline Modal verb & $21.43(39)$ & $13.14(31)$ & 4.491 & $0.034^{\star}$ \\
\hline Noun & $19.89(8)$ & $4.66(11)$ & 3.580 & 0.058 \\
\hline Passivization & $3.30(6)$ & $1.69(49)$ & 0.547 & 0.459 \\
\hline Question form & 0 & $1.27(3)$ & 0.888 & 0.346 \\
\hline Time reference & $0.55(1)$ & $5.08(12)$ & 5.590 & $0.018^{\star}$ \\
\hline
\end{tabular}

Spanish speakers also used more impersonal expressions, which were found to be significant $(p=0.008)$, such as the example produced by subject 2 "se piensa que los universitarios únicamente se preparan en la Universidad para adquirir conocimientos" (it is thought that University students only prepare themselves at University to acquire knowledge). Spanish speakers also showed a more frequent use of time reference as a hedge. This difference was found to be significant ( $p=0.018$ ), as in the example produced by subject 21: "En conclusión estoy más o menos de acuerdo con el segundo punto de vista" (In conclusion, I roughly agree with the second point of view). In contrast, English speakers used time reference to express hedging only once: "University education broadly helps overall development of individual growth" (subject 1). Chi square analysis also showed significant differences in the use of modal verbs $(p=0.034)$, i.e. English speakers produced more modal verbs than Spanish speakers; for example, subject 18 wrote: "One may argue the intent of any collegiate level education is to prepare students to excel in the workforce after graduation".

\subsubsection{Spanish learners of English as an L2 use of hedges in their L2 and in their L1}

As can be observed in table 4, English L2 learners behaved in a similar way both in their L1 and in their L2. Significant differences are indicated with asterisks. They were only found in the 
use of adjectives ( $p=0.037)$ and modal verbs ( $p=0.013)$ as hedging items. In their L2 they used more adjectives and more modal verbs as hedges than they did in their $L 1$, as the following examples show: "we cannot reduce University to one single purpose as it has a considerable amount such as finding better jobs" (subject 11) and "...as students may believe that going to university offers more chances" (subject 2). The frequent use of modal verbs by L2 learners can be due to transfer of training, since Spanish teachers usually emphasize the relevance of modal verbs as hedges in English.

\section{TABLE 4}

Use of hedging devices by English L2 learners in their LI (Spanish) and in their L2 (English)

\begin{tabular}{lcc|c|c} 
& LI SPANISH & L2 ENGLISH & & \\
\hline \multicolumn{1}{c|}{ HeDGES } & & & CHI-SQUARE & P VALUE \\
\hline Adjective & $3.83(9)$ & $8.85(23)$ & 4.3407 & $0.037^{*}$ \\
\hline Adverb & $18.30(43)$ & $13.85(36)$ & 1.5070 & 0.220 \\
\hline If-clause & $2.98(27)$ & $2.69(7)$ & 0.000 & 1.000 \\
\hline $\begin{array}{l}\text { Impersonal } \\
\text { expression }\end{array}$ & $17.02(4)$ & $14.23(37)$ & 0.5347 & 0.465 \\
\hline Lexical verb & $20.85(47)$ & $15.00(39)$ & 2.5045 & 0.113 \\
\hline Modal verb & $14.89(35)$ & $24.23(63)$ & 6.2020 & $0.013^{*}$ \\
\hline Noun & $11.49(27)$ & $14.62(38)$ & 0.8011 & 0.371 \\
\hline Passivization & $2.55(6)$ & $1.54(4)$ & 0.2318 & 0.630 \\
\hline Question form & $1.70(4)$ & $1.15(3)$ & 0.0182 & 0.893 \\
\hline Time reference & $6.38(15)$ & $3.85(10)$ & 1.1697 & 0.279 \\
\hline
\end{tabular}

\subsubsection{English native control group and learners use of hedges in L2 English}

Table 5 indicates the number of hedging devices produced by English native speakers and L2 learners (see the table on the next page).

Table 5 shows that English speakers and L2 learners showed similar results in the use of adjectives, adverbs, if-clauses, modal verbs, nouns, passivization, question forms and time reference as hedges. However, significant differences were observed in the use of impersonal expressions ( $p=0.006)$ and lexical verbs $(p=0.015)$ as hedging devices. English speakers used lexical verbs more often than L2 learners did, as can be illustrated in the example produced by subject 23: "I believe both views are true". In contrast, L2 learners used impersonal expressions more frequently than English speakers did, such as the one produced by subject 16: "It is widely believed that University helps its students to achieve 


\section{TABLE 5}

Use of hedges by the English native speakers control group and L2 learners of English

\begin{tabular}{lcc|c|c}
\hline \multicolumn{1}{c|}{ HedGES } & L1 ENGLISH & L2 ENGLISH & & \\
\hline Adjective & & & CHI-SQUARE & P VALUE \\
\hline Adverb & $10.99(20)$ & $8.85(23)$ & 0.342 & 0.558 \\
\hline If-clause & $18.13(33)$ & $13.85(36)$ & 1.185 & 0.276 \\
\hline $\begin{array}{l}\text { Impersonal } \\
\text { expression }\end{array}$ & $5.49(10)$ & $2.69(7)$ & 1.579 & 0.209 \\
\hline Lexical verb & $5.49(10)$ & $14.23(37)$ & 7.704 & $0.006^{*}$ \\
\hline Modal verb & $24.73(45)$ & $15.00(39)$ & 5.962 & $0.015^{*}$ \\
\hline Noun & $21.43(39)$ & $24.23(63)$ & 0.329 & 0.566 \\
\hline Passivization & $9.89(18)$ & $14.62(38)$ & 1.754 & 0.185 \\
\hline Question form & $3.30(6)$ & $1.54(4)$ & 0.807 & 0.369 \\
\hline Time reference & 0 & $1.15(3)$ & 0.749 & 0.387 \\
\hline
\end{tabular}

better jobs". This is compatible with the frequent use of impersonal expressions in the spanish native control group, which seems to indicate the occurrence of crosslinguistic influence from Spanish.

\subsubsection{Spanish native control and Spanish learners of L2 English use of hedges in Spanish}

Table 6 shows the number of hedging devices used by the Spanish native control group and learners of English as a L2 in their native language (Spanish) (see the table on the next page).

As table 6 shows, Spanish monolingual LI speakers in the control group and Spanish learners of $L 2$ English showed similar results in the frequency of use of adjectives, if-clauses, impersonal expressions, lexical verbs, modal verbs, passivization, question forms, and time reference as hedging devices. In contrast, they showed significant differences in the use of adverbs ( $p=0.003$ ) and nouns ( $p=0.011$ ), i.e. the Spanish native control group used significantly more adverbs than the Spanish learners of L2 English group in their L1 did. The Spanish native control group also used significantly more adverbs than the English native control group. With regard to nouns, Spanish learners of L2 English used more nouns in their L1 than the Spanish native control group, as in "Esto se debe a la tendencia a creer..." (This is due to the tendency to believe) (subject 24). 


\section{TABLE 6}

Use of hedges by Spanish L1 speakers in the control group and learners of L2 English in their LI (Spanish)

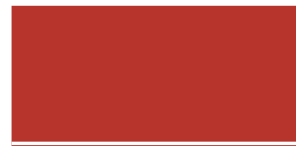

HEDGES
SPANISH NATIVE SPEAKERS (CONTROL GROUP)

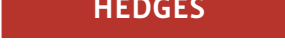

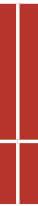

\section{SPANISH LEARNERS OF ENGLISH IN THEIR LI SPANISH}

\begin{tabular}{lcccc} 
Adjective & $8.47(20)$ & $3.83(9)$ & 3.629 & 0.057 \\
\hline Adverb & $30.51(72)$ & $18.30(43)$ & 8.863 & $0.003^{*}$ \\
\hline \begin{tabular}{l} 
If-clause \\
\hline $\begin{array}{l}\text { Impersonal } \\
\text { expression }\end{array}$
\end{tabular} & $1.69(4)$ & $2.98(27)$ & 0.381 & 0.537 \\
\hline Lexical verb & $13.98(33)$ & $17.02(40)$ & 0.614 & 0.433 \\
\hline Modal verb & $13.49(46)$ & $20.85(47)$ & 0.064 & 0.800 \\
\hline Noun & $4.66(11)$ & $14.89(35)$ & 0.174 & 0.677 \\
\hline Passivization & $1.69(4)$ & $11.49(27)$ & 6.510 & $0.011^{*}$ \\
\hline Question form & $1.27(3)$ & $2.55(6)$ & 0.107 & 0.744 \\
\hline Time reference & $5.08(12)$ & $1.70(4)$ & 0.000 & 0.995 \\
\hline
\end{tabular}

\section{Discussion}

Our first research question aimed at knowing whether L1 English native speakers and LI Spanish native speakers in the control group would differ in the use of hedging devices. Findings showed that English native speakers produced a total of 182 hedges, while Spanish native speakers used 236 hedges. Chi-square analysis revealed these results to be significant $(p=0.008)$. With regard to differences in the types of hedging devices, Spanish speakers used more adverbs, impersonal expressions and time reference as hedges. English speakers used more modal verbs than Spanish speakers. In the rest of cases both groups showed similar results. Both Spanish and English speakers have studied academic writing in their respective universities and being familiar with this skill may have lead them to show few differences in using it; however, it is interesting to observe that Spanish speakers used hedging devices to a larger extent. Similar results were found by Clyne (1991), who observed that German speakers used more hedging devices than English speakers did. He attributed this to socio-cultural reasons. In our data it may be the case that the attention given to essay writing and structure in Spanish at University makes students more aware of the use of hedging devices than their English-speaking counterparts.

Our second research question focused on whether L2 learners would differ from L1 native speakers of English in the control group. The comparison between both groups revealed that 
a significant difference was found in the use of hedges ( $p=0.000)$. L2 learners produced more hedging devices than English native speakers in the control group. This result is in contrast with the results found by Hinkel (2005). In his study L2 writers used fewer hedging devices than Lı speakers. His study includes data from native speakers of English and data from nonnative speakers of English from different Lis and native speakers are compared with nonnative speakers. Choi and Ko (2005) also found that L2 expert writers used hedging devices less frequently than Korean students of English as an L2. They attributed this to the fact that their study was based on sentence types with hedging expressions since they followed Crompton (1997), while studies such as Hyland and Milton (1977), Hyland and Tse (2004), which were based on lexical devices, obtained similar results in the use of hedging devices by L1 and L2 writers. In our study we followed Hyland's (1994) typology and yet we observed that L2 writers employed more hedging devices than English L1 writers. This may be due to the occurrence of crosslinguistic influence. Our subjects use more hedging devices in the L 2 in the same way as they use more hedging devices in Spanish L1, i.e. both Spanish native speakers and L2 learners used more hedging devices than English native speakers did. This seems to be corroborated by the fact that L2 learners behaved in a similar way in the use of hedges in their L1 as Spanish native speakers did in the control group. Both Spanish native speakers in the control group and L2 learners, both in their L1 and in their L2, produced significantly more hedging devices than the English native speakers group.

Differences were also observed in the use of some hedging devices. English speakers produced more instances of lexical verbs than L2 learners. Lexical verbs seem to be more common for English speakers while Spanish L2 learners of English rely more on impersonal expressions. L2 learners used more impersonal expressions than English speakers. If we compare this result with the findings in the Spanish control group, it seems that $L 2$ learners behaved in a similar way to Spanish native speakers in the control group. It might be the case that crosslinguistic influence from Spanish made L2 learners resort to impersonal expressions as often as native Spanish speakers in the control group did. At the same time, when we observe how these learners behaved in their LI with regard to impersonal expressions they produced a similar number of impersonal expressions in their L1 as the Spanish group of native speakers did. Therefore, there seems to be evidence to say that crosslinguistic influence from L1 led L2 learners to resort to impersonal expressions more frequently than English L1 speakers did. As all learners show the same level (B2), this cannot be said to be related to differences in language proficiency.

Our third research question aimed at knowing whether LI Spanish speakers learning English as a Second language would differ from Lı monolingual Spanish speakers in their use of hedges in their L1. Findings showed that Spanish speakers in the control group produced 236 hedges and L2 learners 235 in their Spanish L1. Both groups produced hedging devices in similar proportions. A closer look at the different types of hedging devices revealed that Spanish speakers in the control group used significantly more adverbs than L2 learners in their L1 
Spanish did. It must be said that the Spanish native control group also produced more adverbs as hedging devices than the English native control group did. The comparison between L2 learners and English native speakers also revealed that L2 learners used adverbs slightly more than English native speakers did. In other words, L2 learners behaved in a different way both in their Spanish L1 and their English L2 from the Spanish and the English control groups. Apparently both systems (L1-L2) appear to converge in the learners' mind regarding their use of adverbs, differing both from monolingual Spanish and monolingual English speakers. Pavlenko (2011) defines convergence as differentiation of bilingual L1 and L2 performance from L1 and L2 monolingual speakers of their respective languages. Brown and Gullberg's (2013) analysed LI-L2 convergence in motion events among speakers of B2 proficiency level, comparing descriptions of motion from monolingual English and Japanese speakers to L1 and L2 descriptions from Japanese users of English as a second and foreign language. They analysed the concatenation of clauses produced to express Manner and Path of motion. Monolingual groups did not show many differences but bilinguals used more multi-clause constructions both in their L1 and L2 providing evidence of convergence, showing restructuring of bilingual systems. In our study learners also show B2 level. Although most studies on convergence provide evidence of a multicompetent construct in bilingual speakers, the present study, in line with Brown and Gullberg (2013), also seems to provide evidence that convergence can happen at lower levels of proficiency, which suggests that L2 learners restructure linguistic conceptualization. In our study, results showed that learners' use of adverbs as hedging devices in their L1 and in their L2 converge. This seems to provide evidence that in lower levels of proficiency (B2) there appears to be co-existence of a common construct as there is knowledge of more than one language in the same mind even with limited exposure to the L2. This should be taken into account in the teaching of hedging, both the learner's L1 and L2 should be considered when they are learning academic writing as convergence suggests that the $L 1$ and the $\mathrm{L} 2$ are not isolated.

With regard to nouns, Spanish learners of L2 English used more nouns in their L1 than the Spanish native control group. It can also be observed that in their L2 they also employed more nouns than English native speakers did although the difference was not significant. Therefore, this does not seem to be a case of convergence. This may be due to crosslinguistic evidence from their $L 2$ to their $L 1$ since in the $L 2$ they show a tendency to produce more nouns than English speakers, although this tendency is not significant. This also seems to show evidence that languages in the multicompetent mind are in continuous interaction. The use of nouns as hedging devices in the L2 seems to influence the L1, i.e., as Cook (2016) mentions, part of the $L 2$ influences the $L 1$, which takes use to our third question. It focuses on whether there would be evidence of crosslinguistic influence and/or convergence across groups. As has been observed in the answers to research questions 1,2 and 3 , there appears to be evidence of crosslinguistic influence in the total number of hedging devices used by Spanish speakers and L2 learners, both of them use significantly more devices than English native speakers did. Moreover, evidence of crosslinguistic influence is also found in the use 
of impersonal expressions by L2 learners, they used a similar number of them as Spanish speakers in the control group did, and significantly less than English native speakers. Finally, as mentioned above, evidence of LI-L2 convergence was found in the use of adverbs in the learners' group.

As can be observed, using the learners' total system ( $\mathrm{L}$ I and L2), as well as two baseline native speakers' groups has a number of strong points, first it allowed us to obtain evidence of crosslinguistic influence across languages, which can be proved and not simply assumed. Secondly, using learners with the same proficiency level and collecting data in their LI has allowed us to distinguish the effect of crosslinguistic influence from proficiency in the use of hedging devices in academic writing. For example, in Hyland's study (2000) it was not possible to determine whether some of the results were due to language proficiency or crosslinguistic influence because data were not collected in the learners' total system. Moreover, it has shown evidence of convergence in the use of adverbs to express hedging. It has also allowed us to prove that an $\mathrm{L} 2$ learner is neither like a native speaker of the target language nor like a monolingual speaker of the $L 1$.

\section{Conclusion}

Most studies on hedging in L2 writing have focused on the hedging devices used by L2 learners or on the comparison between those employed by native speakers vs. nonnative speakers. The present study has been conducted from the multicompetence framework, where the learner is considered to be a different individual both from the native speaker of the target language and the monolingual Lı speaker. This has allowed us to observe the difference in the use of hedging devices across the learners' total system, i.e. their L1 and L2. Moreover, including data from baseline LI control groups (English and Spanish) has allowed us to analyse the possible occurrence of crosslinguistic influence and convergence.

Findings have shown that English and Spanish speakers in the control groups differed in the use of adverbs, impersonal expressions, modal verbs and time reference as hedging devices. With regard to L2 learners use of hedges in their L1 Spanish and their L2 English, they showed significant differences in the use of adjectives and modal verbs. The English native speakers control group and the group of Spanish learners of L2 English differed in the use of impersonal expressions and lexical verbs as hedging devices. Finally, the comparison between the Spanish native speakers control group and the group of Spanish learners of L2 English in their use of hedges in Spanish revealed significant differences in the use of adverbs and nouns. Moreover, evidence of crosslinguistic influence was found in the number of hedging devices used since both Spanish speakers and L2 learners produced more hedges than English native speakers. It was also found in the use of impersonal expressions; both Spanish speakers and L2 learners used these hedging devices more often than English native speakers did. Finally, 
evidence of convergence was found in the use of adverbs as hedging devices by Spanish learners of L2 English as they showed a preference for using fewer adverbs as hedges in their Lı Spanish than Spanish monolinguals did and slightly more in their L2 English than English native speakers did, differing both from monolingual Spanish and monolingual English speakers. It can be observed that, in these results, convergence affects not only bilingual groups but also lower proficiency levels, and the occurrence of both crosslinguistic influence and convergence indicates a continuous interaction of the different languages in the learner's mind.

Some implications can be drawn from this study. Hedging devices in second language academic writing should not be analysed in isolation. Pedagogy in the field of L2 academic writing should consider that a learner's performance in L2 writing is not isolated from his/her performance in the L1 as languages co-exist in the multicompetent mind. Teaching materials could include examples of the use of hedges in the learner's total system (L1- L2 or L1-L2-Ln). Further studies could include the analysis of hedging devices from the same group of participants in multiple language acquisition by collecting data both in their L1 and $L 2$ and $L n$ so as to observe how the different languages interact and affect the use of hedges in academic writing.

\section{Acknowledgements}

I would like to thank Próspero García for his help in the data collection among native speakers of English and Vivian Cook for his comments on an earlier draft to this paper. All remaining errors are mine.

\section{References}

ARCHIBALD, Alasdair, 2001: "Targeting L2 writing proficiencies: instruction and areas of change in students' writing over time”, International Journal of English Studies 1 (2), 153-174.

BACKus, Ad, 2004: "Convergence as a Mechanism of Language Change”, Bilingualism: Language and Cognition 7 (2), 179-181.

BLoor, Meriel, and Thomas BLoor, 1991: "Cultural expectations and socio-pragmatic failure in academic writing" in Penny Adams, Brian Adams and Peter Howarth (eds.): Socio-cultural issues in English for Academic Purposes. Review of ELT, London: Modern English Publications, 1-13.

BREITKOPF, Anna, 2005: "Hedging in deutschen und russischen wissenschaftlichen Aufsätzen: sprachliche und funktionale Unterschiede" in Armin Wolff, Claudia Riemer and Fritz Neubauer (eds.): Sprache lehren - Sprache lernen, Regensburg: Materialien Deutsch als Fremdsprache, 74, 293-325. 
BREITKOPF, Anna, 2006: Wissenschaftsstile im Vergleich: Subjektivität in deutschen und russischen ZeitschriftenartikeIn der Soziologie, Freiburger Dissertationsreihe 11, Freiburg i. Br.: Rombach.

Brown, Amanda, and Marianne GullberG, 2008: "Bidirectional crosslinguistic influence in LI-L2 encoding of manner in speech and gesture”, Studies in Second Language Acquisition 30 (2), $225-251$.

Brown, Amanda, and Marianne GullberG, 2010: "Changes in encoding of path of motion after acquisition of a second language", Cognitive Linguistics 21 (2), 263-286.

Brown, Amanda, and Marianne GuLlBerg, 2013: "L1-L2 convergence in clausal packaging in Japanese and English”, Bilingualism: Language and Cognition 16, 477-494.

Brown, Penelope, and Steven Levinson, 1987: Politeness: Some universals in language usage, Cambridge: Cambridge University Press.

BuLlock, Barbara, and Almeida Jacquelyne ToRIBIo, 2004: "Introduction: Convergence as an Emergent Property in Bilingual Speech", Bilingualism: Language and Cognition 7 (2), 91-93.

Clyne, Michael, 1987: "Cultural differences in the organization of academic texts", Journal of Pragmatics 11, 211-247.

Clyne, Michael, 1991: "The sociolinguistic dimension: The dilemma of the German-speaking scholar" in Hartmut Schroder (ed.): Subject-oriented texts: Languages for special purposes and text theory, Berlin \& New York: Walter de Gruyter, 49-68.

Cook, Vivian, 2003: Effects of the second language on the first, Clevedon: Multilingual Matters.

Cook, Vivian, 2012: “The native speaker and Multicompetence” in Peter Robinson (ed.): Routledge Encyclopedia of Second Language Acquisition, London: Routledge, 447-450.

Cook, Vivian, 2016: "Premises of multicompetence" in Vivian Cook and Wei Lı: The Cambridge Handbook of Linguistic Multicompetence, Cambridge: Cambridge University Press, 1-25.

Cook, Vivian, and Wei LI, 2016: The Cambridge Handbook of Linguistic Multicompetence, Cambridge: Cambridge University.

CROMPTON, Peter, 1997: "Hedging in academic writing:some theoretical problems", English for Specific Purposes 16, 271-287.

CHEN, Hi, 2010: "Contrastive learner corpus analysis of epistemic modality and interlanguage pragmatic competence in L2 writing", Arizona Working Papers in SLA and Teaching 17 (2), 7-51.

CHol, Yeon Hee, and Mi-Sook Ko, 2005: "Hedging in EFL Academic writing of Korean Posgraduates", English Teaching 60 (1), 3-27. 
Grosjean, Francois, 1998: "Transfer and language mode", Bilingualism: Language and Cognition $1(3), 175-176$.

Gullberg, Marianne, and Peter InDEFrey, 2003: Language Background Questionnaire. Developed in The Dynamics of Multilingual Processing, Nijmegen: Max Planck Institute for Psycholinguistics.

HinkEL, Eli, 2005: “Hedging, inflating, and persuading in L2 academic writing”, Applied Language Learning 14 (2), 29-54.

HINKEL, Eli, 2009: "The effects of essay topics on modal verb uses in L1 and L2 academic writing", Journal of Pragmatics 41 (4), 667-683.

HoLmes, Janet, 1982: "Expressing doubt and certainty in English", RELC Journal 13, 19-28.

Huebler, Axel, 1983: Understatements and Hedges in English (Pragmatics and Beyond 4/6), Amsterdam: John Benjamins.

HyLAND, Ken, 1994: "Hedging in Academic Writing and EAP textbooks", English for Specific Purposes 13 (3), 239-256.

HyLAnd, Ken, and John MıLton, 1997: "Qualification and Certainty in L1 and L2 Students' Writing”, Journal of Second Language Writing 6 (2), 183-205.

HyLAND, Ken, 1998: "Writing without conviction? Hedging in science research articles", Applied Linguistics 17 (4), 433-454.

HyLAND, Ken, 2000: Disciplinary discourses: Social interactions in academic writing, London: Longman.

HyLAnd, Ken, and Polly Tse, 2004: "Metadiscourse in academic writing: A reappraisal", Applied Linguistics 25 (2), 156-172.

JARVIS, Scott, 2002: "Methodological rigor in the study of transfer: Identifying LI influence in them interlanguage lexicon”, Language Learning 50 (2), 245-309.

Kreutz, Heinz, and Annette Harres, 1997: Some observations on the distribution and function of hedging in German and English: Academic writing,culture,and styles of academic discourse, Mouton de Gruyter: Berlin.

LAKOFF, Georges, 1972: "Hedges: A study in meaning criteria and the logic of fuzzy concepts", Chicago Linguistic Society Papers 8, 183-228.

Lyons, John, 1977: Semantics, Cambridge: Cambridge University Press.

MARTA, Monica Mihaela, 2017: “Hedging: Recent trends in written academic discourse”, Bulletin Stiintific Fascicula Filologie 1, 39-47. 
Mauranen, Anna, 1997: "Hedging in language revisers' hands" in Raija MarkKanen and Hartmut SCHRODER (eds.): Hedging and discourse: Approaches to the analysis of a pragmatic phenomenon in academic texts, Berlin and New York: Walter de Gruyter, 115-133.

MYERS, Greg, 1989: "The pragmatics of politeness in scientific articles", Applied Linguistics 10 (1), $1-35$.

Nurmukhamedov, Ulugbek, and Soo-Hyon KIm, 2009: "Would you perhaps consider hedged comments in ESL writing", ELT Journal 64 (3), 272-282.

Ortega, Lourdes, 2016: "Multi-competence in second language acquisition:inroads into the mainstream?" in Vivian Cook and Wei Lı (eds.): The Cambridge Handbook of Linguistic Multicompetence, Cambridge: Cambridge University Press, 50-76.

Oxford Quick Placement Test, 2001. University of Cambridge Local Examinations Syndicate.

Pavlenko, Aneta, 2011: Thinking for speaking in two languages, Bristol: Multilingual Matters.

Poveda Cabanes, Paloma, 2007: "A contrastive analysis of hedging in English and Spanish architecture project descriptions”, Resla 20, 139-158.

Salager-Meyer, Francoise, 1994: "Hedges and textual communicative function in medical Emglish written discourse", English for Specific Purposes 13, 149-170.

Scarcella, Robin, and Joanna Brunak, 1981: "On speaking politely in a second language", International Journal of the Sociology of Language 27, 59-75.

SKELton, John, 1988a: "The care and maintenance of hedges", ELT Journal 41 (1), 37-43.

SKELTON, John, 1988b: "Comments in academic articles", Applied Linguistics in Society, London: CILT/BAAL.

Treffers-Daller, Jeanine, and Raymond Mougeon, 2005: "The Role of Transfer in Language Variation and Change: Evidence from Contact Varieties of French", Bilingualism: Language and Cognition 8 (2), 93-98.

TRUMPP, EC, 1998: Kultur- und textsortenspezifische Vertextungsstrategien. Eine kontrastive fachtextlinguistische Untersuchung zum Kommunikationsbereich der Sportwissenschaft: Englisch - Deutsch - Französisch, Tübingen: Narr.

VASSILEVA, Irena, 1997: Hedging in English and Bulgarian academic writing, culture, and style in academic discourse, Mouton de Gruyter: Berlin.

Ventola, Eija, and Anna Mauranen, 1990: Tutkijat ja englanniksi kirjoittaminen, Helsinki: Helsinki University Press. 